\title{
Phylodynamic analysis of hepatitis delta virus genotypes 1 and 2 in the Russian Federation
}

APASL Single Topic Conference Delta Hepatitis June 27-28, 2019 Baku, Azerbaijan

Anastasia Karlsen ${ }^{1}$

${ }^{1}$ Russian Federation, karlsen12@gmail.com

Background: Hepatitis delta virus (HDV) infection has an uneven prevalence in the Russian Federation, with low infection rates in European part. But, there are several endemic regions in the country, such as Republic Saha (Yakutia), Republic Tuva and Republic Dagestan. The aim of this study was to elucidate the transmission history of HDV in the Russian Federation Materials and methods: Total 161 sequences coding HDV R0 region (321 nt) were amplified and sequenced from samples obtained from patients with chronic hepatitis delta from Tuva $(n=127)$, Yakutia ( $n=7)$, and Dagestan ( $n=27)$. HDV genotype was assigned according to ICTV 2018 classification. Resulting database of HDV sequences of genotype $1 \quad(n=157)$ and 2 $(n=4)$ was supplemented with 454 sequences from GenBank with known the year and the country of isolation, which had divergence at least $2 \%$. Bayesian analysis was performed by using the software package BEAST v1.8.3, ESS was $>200$. Results: The phylodynamic analysis demonstrated that HDV genotype 1 was introduced to the Russian Federation in the 1960s (95\% HPD interval: 1958 - 1978). The introduction has occurred in parallel from two directions. The first direction was from the islands in the Pacific Ocean, through Yakutia, further spreading through the territory of Russia. Sequences from Pakistan, Israel, Poland, Georgia and Mongolia also belonged to this cluster. The second direction of HDV introduction was from Europe. As a result of this event, two closely related strains have formed on the territory of Russia with estimated time of divergence in the early 1980s (95\% HPD interval: 1966 -1990). The first strain is endemic in Dagestan, Tuva and Samara. The second strain formed the monophiletic group of sequences from Tuva, with common ancestors in Romania, Mongolia and Pakistan. In addition to the abovementioned large clusters, there are also small clusters or even single sequences isolated resulted from the continuous migration between Russia and Central Asia. HDV genotype 2 originates from the eastern part of the Asian continent, and was introduced in Yakutia around 1940s (95\% HPD interval: 1912-1949). Since then this genotype had a stable circulation in Yakutia, but it did not extend beyond the region, being absent in other parts of Russia. Conclusion: The evolution history of current HDV strains in the Russian Federation spans about 80 years. Our data suggest multiple introductions of viral strains in 20th century.

"Published on behalf of the Azerbaijan Gastroenterology and Hepatology Association for the APASL STC Hepatitis Delta. All rights reserved. (C) The Author 2019. For permissions please email: editor@ejcs.org or uptodate.az@gmail.com 